\title{
Identifying Argumentation Skills Using Three Tier Test on Pre-service Physics and Biology Teachers
}

\author{
E. Suryani ${ }^{1}$, Y. Yusiran ${ }^{2}$, O. Hairullah ${ }^{3}$, S. Siswanto ${ }^{4}$, N. Nurfathurrahmah ${ }^{5}$, \\ Ariyansyah $^{6}$ \\ \{yusiranbima@gmail.com ${ }^{2}$ \} \\ Department of Biology Education, STKIP Bima, Kota Bima, Nusa Tenggara barat, Indonesia ${ }^{1,3,5,6}$, \\ Department of Physics Education, STKIP Bima, Kota Bima, Nusa Tenggara barat, Indonesia ${ }^{2}$, \\ Department of Natural Science Education, Universitas Tidar, Kota Magelang, Jawa Tengah, Indonesia ${ }^{4}$
}

\begin{abstract}
Argumentation skills are pivotal aspects have to be mastered by college students. Therefore, it is crucial to identify argumentation skills for mapping learning activities. The study utilizes content analysis as a qualitative research method with fifty participants. They focus on being physics and biology teachers for the future. To analyze the argumentation skills of them, a three-tier test is developed. This test has a specific characteristic due to providing a certainty index or confidence rating of argument aspects proposed. Various types of students' arguments are coded in five codes: strong scientific argument, intermediate scientific argument, a weak argument, cannot propose an argument, and invalid argument. The result shows that weak argument is the dominant type in which the quality of this argument consists of claims and data with low certainty index. The implication of this present study is to generate a certain approach to teach argumentation skills in pre-service teachers.
\end{abstract}

Keywords: Three-tier test, Argumentation skill, Pre-service teacher

\section{Introduction}

The demand for the modern world requires the thinking skill to face problems in the 21 st century. In this era, one does not only have to master a conceptual understanding of knowledge but also should own the scientific skills [1]. One of the scientific skills is argumentation skills in which this skill is common in science [2]. As we know, the purpose of science itself is to yield new knowledge of the natural world. Two crucial practices to obtain this goal are argument and critique. Through argumentation, scientists utilize to make their case for new ideas whether they are new theories, novel ways of collecting data, or a fresh interpretation of old data. On the other hand, critique is not some peripheral feature of science but it is the core of its practice [2]. The building of reliable knowledge is almost impossible if there is no argumentation and evaluation-in this context is critique. Therefore, the existence of argumentation skills is still required to produce new knowledge and a part of thinking skills that should be trained to pre-service teachers as a way to prepare qualified teachers in the future.

Over the past two decades, there is a huge body of research related to argumentation skills. Some research focused on to improve the quality instruction in science in underpinning students' argumentation skills. For instance, Murphy et al [1] used the quality talks of discussion to improve students' argumentation performance. Others focused on investigating 
the role of inquiry learning as a way to help students learn how to create written arguments [3],[4]. Also, the researcher from Turkey utilized explicit argumentation instruction that trains students to depict argumentation skills [5]. In a different context, a science education researcher investigated the role of socio-scientific issues to assess the level of pre-service written arguments [6]. If considering these previous researches of argumentation skills, most research was directed in developing specific instruction and assessment to assess argumentation skills. However, there is little research to focus on using the tier test and certainty index to assess pre-service teachers' argumentation skills. This is very crucial because it provides a certainty index of pre-service teachers when proposing written arguments. Therefore, this present study investigates and identifies pre-service teachers' argumentation skills using three-tier tests. The use of this type of test aims to reveal the level of pre-service teachers' certainty in providing aspects of argument such as data, claim, warrant, and rebuttal. In other words, this study categorizes the level of argumentation based on several codes provided, namely strong scientific argumentation, intermediate scientific argumentation, weak argumentation, cannot propose argumentation, and invalid argumentation whether pre-service teachers own a strong argumentation or not. The one research question that is developed in this study is how does the proportion of levels of argumentation in each code?

\section{Argumentation Skill}

The argumentation skill is one of the thinking skills that should be mastered by college students (i.e. pre-service teachers). Its reason is that they should be facilitating their students to acquire the argumentation skill. If they have a lack of argumentation skills, it can be predicted that they will flaw in teaching arguments. Therefore, some science educators have to have a better understanding of argumentation.

The basic framework of argumentation skill always refers to Toulmin's argument model. It offers a generic representation of all arguments that claim to knowledge [2],[7]. This model of argument consists of four aspects: claim, data, warrant, and rebuttal (see Figure 1.). How does an argument constructed in this model? To respond to this question, we have to know the definition of these aspects of the argument. Claim refers to the statement that is supported by data. Then, the relationship between data and claim is justified by a warrant. Warrants often rest on theoretical assumptions that are only tacitly acknowledged [7]. Then, the limits of validity of the claim are expressed by a qualifier. Arguments emerge when efforts are made to rebut or refute the claim either by attacking the validity of data or validity of the warrant [2],[7]. 


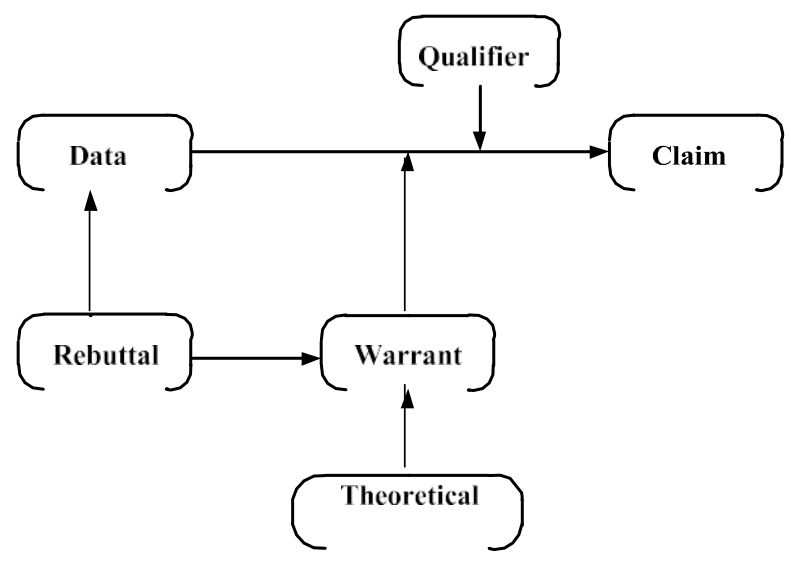

Fig. 1. Toulmin's Argument Model.

In the context of argumentation research, almost one-half of decades ago, some researchers [8],[9],[10] represented a compelling case to support the introduction of argumentation as a crucial skill for students not only in high school but also in college. They believe that the process of argumentation through the construction of argument is the core of the practice of science. Its rationality is that scientific knowledge is scientifically arranged through critique, replication, and evaluation [11]. In this study, students' argumentation skills would be assessed using the three-tier test in which it comprises three levels of answer to assert the level and quality of students' argumentation.

\section{Three-Tier Tests}

There are many types of tests utilized to assess students' understanding and conception. One of these is the two-tier test that is a popular type of paper-pencil tool because the test is effective to be used in a large sample of students [12]. Then, this type of test develops to be a three-tier test. The focus or goal of the test is still consistent to assess students' understanding and conception of physics concepts. For the two-tier test, this comprises chntent tier and reason tier. This type of test has a limitation in which it can differentiate mistakes due to a lack of knowledge so that the differentiation of mistakes from guessing cannot be determined. Based on this argument, many researchers develop a three-tier test as a diagnostic test [12]. This test aims to ignore guessing conducted students during the test. Despite content tier and reason tier, the three-tier test provides a new element, namely certainty index or confidence rating.

In this present study, we carry this type of test to assess students' argumentation skills. We also alter the elements contained in the test. The first tier is claim tier in which it is valued by the true or false claim. Then, the second tier is the confidence rating to determine the level of certainty index in proposing a claim. Finally, the third tier is data and warrant that are used to underpin the claim. The big differentiation of this test from the other three-tier tests is it elaborates on the component of Toulmin's' model argument to be utilized as a tier in recognizing strong argument. 


\section{Method}

This study employs a qualitative research method-a content analysis [13]. We obtain students' written arguments using a three-tier test. 50 participants are physics and biology preservice teachers who take the course of fundamentals of physics. They should propose their argument related to one mechanics problem provided. They then present their scientific argument using a three-tier test format. We code the students' argumentation based on the tiers proposed: claim, confidence rating, and data-warrant. There are five codes of students' argumentation skill: strong scientific argument, intermediate scientific argument, a weak argument, cannot propose an argument, and an invalid argument. The explanation of each code can be seen in Table 1.

Table 1. Five code of level of students' argument.

\begin{tabular}{cccc}
\hline Code & \multicolumn{2}{c}{ Three-tier test model } \\
\cline { 2 - 4 } & Claim & Confidence Rating & Data-Warrant \\
\hline Strong scientific argument & True & Confident & True-True \\
Intermediate scientific argument & True & Confident & True-False \\
Weak argument & True & Confident & False-False \\
Cannot propose argument & True & Unconfident & False-False \\
Invalid argument & false & Unconfident & False-False \\
\hline
\end{tabular}

All codes are utilized to analyze preservice teachers' arguments. As many as 50 these documents related to the concept of mechanics are analyzed. First, the proportion of each code of the level of the argument is determined. This aims to recognize what the dominant type of argument is in the classroom. Then, the second analysis is to analyze the quality of each code or level of argument. In this analysis, we present and elaborate on the arguments qualitatively. Some pre-service teachers' perceptions also are represented to strengthen why they propose a certain type of argument.

\section{Result and Discussion}

This is a crucial part of the research because of providing some data and discussion. We analyze and discuss a type of datum that is the proportion of pre-service teachers' arguments. The proportion of types of argument is obtained by using five codes designed to determine the level of pre-service teachers' arguments whether they are appropriate with criteria of code or not. We arrange all data in the proportion of each code provided that can be seen in the Table 2. All data represent the number of fifty written arguments obtained that is analyzed using the criteria provided. The written arguments are proposed by pre-service teachers after they do the learning process using a virtual laboratory integrated real-world problem. Normally, they have no problems with the aspects of argument because they learn in several times of meeting in the course. The researchers explain the definition of each aspect of argumentation and they provide the sample that can be followed; this means that they have good knowledge of how to create the argument if considered a structure of the argument. 
Table 2. The proportion of each level of argument based on criteria of code.

\begin{tabular}{lll}
\hline Level of argument & Number & Proportion $(\%)$ \\
\hline Strong scientific argument & 1 & 2 \\
Intermediate scientific argument & 9 & 18 \\
Weak argument & 27 & 54 \\
Cannot propose an argument & 13 & 26 \\
Invalid argument & 0 & 0 \\
\hline
\end{tabular}

The high proportion of the type of pre-service teachers' argument is "weak argument". This means that they can propose a true claim with confidence. They are lack of data-warrant to support their claim. The one that can propose true arguments with high confident shows that they have good basic knowledge related to the problem provided. However, they cannot support the claim by data and warrant. This crucial aspect of the argumentation perspective because proposing false data and warrant refers to the lost understanding of the concept of the problem [8].

The second high proportion of the type of argument is "cannot propose argument". In this context, pre-service teachers just can propose a claim with unconfident certainty. We argue that they do not have enough knowledge related to the problem provided. In another word, they may be guessed to propose the claim. Also, almost one-fifth of pre-service teachers have the capability in proposing a true claim, confident certainty, and supporting the claim with true data. This is interesting because they can link data to support the claim. This shows that they have a leap from data to the warrant. In another word, they recognize how the claim applies [2].

Despite minor of pre-service teachers having a strong scientific argument, there is one that can propose the argument with the true claim, high confident certainty, and true datawarrant. This is a comprehensive argument in which pre-service teachers should have this competence. When they have this skill, they recognize problems well and they make an elaboration to support the true claim. The most important aspect of this level is they can provide a true warrant. To propose a true warrant, they have to have good scientific assumptions so that there is a leap from data to the warrant with the right scientific assumption [2],[3].

\section{Conclusion}

Three-tier test that is frequently utilized in assessing conceptual and perception of students related to concepts of science is an effective alternative tool for identifying preservice teachers' arguments. We can recognize the type of students in which they have difficulty in proposing data to support the claim. Almost half of the pre-service teachers cannot support their claim with true data and warrant. In this context, they still have a good confident certainty in proposing a claim. The implication of this research is to enhance the awareness of researchers or scholars who focus on training argumentation skills. Many preservice teachers or college students should provide a special determination in training data and warrant to support claims because it is a challenging process for many students. 
Acknowledgments. We would like to thank the ministry of higher education and technology that support the fund for the research. We also would like to thank many people that contributed to this study: our colleagues, students, and employer in our institution that supported this study. We hope this article will be an emerging benefit for many scholars in Indonesia.

\section{References}

[1]. Murphy, P. K., Greene, J. A., Allen, E., Baszczewski, S., Swearingen, A., Wei, L., and Butler, A. M.: Fostering high school students' conceptual understanding and argumentation performance in science through Quality Talk discussions. Science Education, Vol. 102, No. 6, pp. 1239- 1264 (2018)

[2]. Osborne, J.: Arguing to learn in science: The role of collaborative, critical discourse. Science, Vol. 328, No. 5977, pp. 463-466 (2010)

[3]. Sampson, V., Grooms, J., and Walker, J. P.: Argument Driven In-quiry as a way to help students learn how to participate in scientific argumentation and craft written arguments: An exploratory study Science Education, Vol. 95, No. 2, pp. 217-257 (2011)

[4]. Siswanto, Gumilar, S., and Subali, B.: Scientific method by argumentation design: learning process for maintaining student's retention. In Journal of Physics: Conference Series, IOP Publishing, Vol. 983, No. 1, pp. 012021 (2018)

[5]. Cetin, P. S.: Explicit argumentation instruction to facilitate conceptual understanding and argumentation skills. Research in Science and Technological Education, Vol. 32, No. 1, pp. 1-20 (2014)

[6]. Aydeniz, M., and Gürçay, D.: Assessing quality of pre-service physics teachers' written arguments. Research in Science and Technological Education, Vol. 31, No. 3, pp. 269-287 (2013)

[7]. Toulmin, S.: The Uses of Argument. Cambridge Univ. Press, Cambridge (1958)

[8]. Duschl, R. A., and J. osborne.: Supporting and Promoting Argumentation Discourse in Science education. Studies in Science Education Vol. 38, No. 1, pp. 39-72 (2002)

[9]. Jimenez-Aleixandre, M. P., A. B. Rodriguez, and R. A. Duschl.: Doing the Lesson or Doing Science: Argument in High School Genetics. Science Education Vol. 84, pp. 757-792 (2000)

[10]. Newton, P., R. Driver, and J. osborne.: The Place of Argumentation in the Pedagogy of School Science.” International Journal of Science Education Vol. 21, No. 5, pp. 553-576 (1999)

[11]. Dawson, V., and Carson, K.: Using climate change scenarios to assess high school students' argumentation skills. Research in Science \& Technological Education, Vol. 35, No. 1, pp. 1-16 (2017)

[12]. Caleon, I., and Subramaniam, R.: Development and application of a three tier diagnostic test to assess secondary students' understanding of waves. International journal of science education, Vol. 32, No. 7, pp. 939-961 (2010)

[13]. Cohen, L., Manion, L., and Morrison, K.: Research methods in education, London: Routledge Falmer 7th ed., pp. 31-30 (2017) 